\title{
Optimization of technology of diode laser mirror processing to maximize the threshold of catastrophic optical degradation
}

\author{
Elżbieta DĄBROWSKA ${ }^{1 *}$, Marian TEODORCZYK ${ }^{1}$, Michą SZYMAŃSKI $^{2}$, ANDRZEJ MALĄG ${ }^{1}$ \\ ${ }^{1}$ Sieć Badawcza Łukasiewicz - ITME, ul. Wólczyńska 133, 01-919 Warsaw, Poland \\ ${ }^{2}$ Warsaw University of Life Sciences, Faculty of Applied Informatics and Mathematics, \\ ul. Nowoursynowska 159, 02-776 Warsaw, Poland
}

${ }^{*}$ Corresponding author: Elzbieta.Dabrowska@itme.edu.pl

\begin{abstract}
In this paper, optimization works on the technology of passivation and optical coatings of laser diode facets are described. The main goal is to increase the optical power at which the catastrophic optical mirror damage occurs. The coatings and passivation processes have been done in an ion source-aided electron-beam evaporator. The essence of passivation was to remove native oxides and produce a native thin nitride layer with simultaneous saturation of the dangling atomic bonds. The procedure has been realized with the help of nitrogen or forming gas $\left(\mathrm{N}_{2}+\mathrm{H}_{2}\right)$ beam. As a result, we present sets of technological parameters allowing to increase the catastrophic optical mirror damage threshold of diode lasers.
\end{abstract}

Keywords: laser diodes, catastrophic optical damage (COD), laser mirrors, semiconductor surface passivation, optical coatings, electroluminescence.

\section{Introduction}

The wide range of diode laser (DL) applications results from their attractive properties, such as high efficiency, small size, the possibility of precise wavelength selection in the technological process, the possibility of temperature tuning, the facility for integration and particularly a very good emitted-power-to-size ratio. The maximum power emitted by DL depends on the advancement degree of active cooling technologies and the level of the laser structure immunity to high density of the radiation power inside the resonator.

Catastrophic optical damage (COD) is viewed as the dominant mechanism limiting the emitted light power of DLs in the optical range from visible to shortwave-near-infrared (SW NIR) subband. If COD applies to the mirrors, it is then called a catastrophic optical mirror damage (COMD) and is a phenomenon manifesting itself in melting of, predominantly, the front facet of the laser, where the optical power is expected to be 
the highest in the cavity. The origin of COMD is explained as a consequence of the technological process itself. Reflecting surfaces are obtained by breaking in semiconductor crystal in the planes of the natural cleavage. The then emerging dangling bonds make surfaces active both electrically and chemically, which, in turn, fosters undesired heat generation during laser operation. Therefore, designing high power DLs requires developing the technologies of:

- passivation of mirror surfaces (PMS) to saturate the dangling bonds and remove residual oxides;

- producing appropriate optical coatings (OC) to ensure high and low reflectivity at the rear and front facet respectively in order to output the largest possible part of the generated radiation through the front mirror.

Optimization of these processes has already been discussed in literature (see for example [1-4]), however, the lack of technological details is noticeable in all cases.

The "basic" E2 passivation process was invented by IBM in the 1990s. After breaking in air, the exposed facets (to be mirrors) were irradiated by unreactive ions ( $\left.\mathrm{Ar}^{+}\right)$ to remove oxides, then followed by the deposition of a thin (1-5 nm), silicon layer for passivation. Much more advanced method relies on the vacuum cleaving, i.e., in an oxygen-free atmosphere, followed by the deposition of a thin, silicon layer [ $\underline{3}, \underline{5}]$. However, very high costs practically eliminate this method. The E2 method proved to be advantageous for moderate-power DLs. With increasing optical power (and mirror temperature) the absorption by a narrow-gap Si layer and the risk of entering Si (n-dopant) into chemical reaction with mirror surface causes this method inadequate.

Application of another widely used passivation technique by wet-chemical sulphation (e.g. using $\left(\mathrm{NH}_{4}\right)_{2} \mathrm{~S}_{x}$ or $\mathrm{S}_{2} \mathrm{Cl}_{2}$ solutions) to laser mirrors [ $[\underline{6}, 7]$ proved to be limited because, in the case of Al-containing heterostructures, chemical etching associated with sulphation with a rate dependent on Al-content causes wavy-like ripples on mirror surface. Another problem is quick degradation of quality of such passivation, so immediate ex situ coating is required.

The nitridation, i.e. creating "native" passivating layers of nitrides of heterostructure materials ( $\mathrm{Ga}, \mathrm{Al}, \mathrm{In}$ ) by irradiation (bombardment) with high-energy ionized nitrogen, is the newest technique of mirrors' protection $[\underline{1}, \underline{3}, \underline{4}]$, proposed by Comlase, Stockholm and connected with the extensive development of nitride technologies.

In this paper, we revisit the problem of PMS and OC providing extensive discussion of the applied methods. Our technological efforts are oriented for increasing the DL's COMD threshold (and simultaneously $[\underline{1}, \underline{3}]$ device lifetime).

Our earlier investigations provided some hints for optimization of DL's facets passivation and coating [ $\underline{8}]$, however, the conclusions are ambiguous. For the following driving regime: pulse width of $t=1 \mu \mathrm{s}$, repetition rate $T=1 \mathrm{~ms}$ and maximum amplitude $I=10 \mathrm{~A}$ (the current source limit), the vast majority of devices did not reach the COD threshold. This may be regarded as confirmation of the high quality of OCs and PMS techniques, but does not allow for optimization. Increasing the pulse width up to $6 \mu \mathrm{s}$ caused that the effect of COD was observed for a large number of chips. However, the results are still ambiguous because COMD then depends on an additional parameter, 
namely pulse width. Moreover, increasing pulse width leads to temperature rise in the entire resonator and thus may initiate COD in the volume. The effect manifested itself in [ $[$ ] as a sudden drop of light power for driving currents exceeding values for which the maximum light power is observed. The investigation of spontaneous emission (electroluminescence (EL)) through the "n-contact-windows" (i.e. intentional stripeshaped discontinuities in the n-contact metallization above the active stripes), done afterwards, revealed numerous signs of degradation in the form of dark lines along the laser axis distant from the mirrors. These results are unique and a bit surprising. They clearly show that COD is not the same as COMD and explain some of our previous cases, when degraded DLs exhibited no damages on mirrors. Clearly, while optimization of PMS or OCs is the object of our interest, the "inside resonator" COD is a process of less importance and it would be advisable to be aware of this effect instead of mirror defects.

\section{The description of the investigated devices and the experiment}

This study is a continuation of investigations reported in []ㅡ. DL chips investigated here emit radiation in the range $910-920 \mathrm{~nm}$, come from one $\mathrm{InGaAs} / \mathrm{AlGaAs} / \mathrm{GaAs}$ heterostructure (schematically shown in Fig. 1) and from wafer processing of scheme described therein [] $]$.

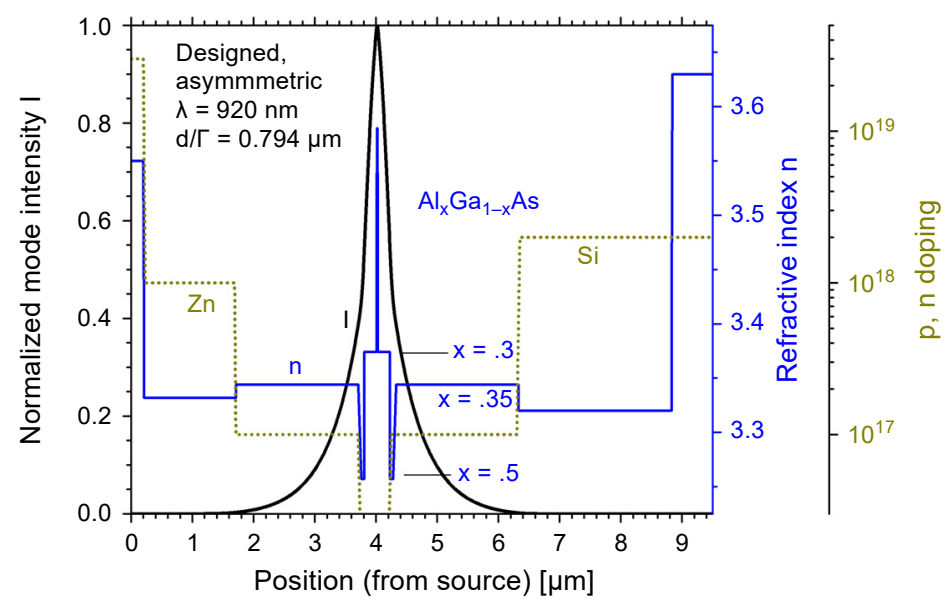

Fig. 1. Schematic view of InGaAs/AlGaAs/GaAs laser heterostructure, namely: refractive index distribution and chemical composition (blue color), concentration of Si and $\mathrm{Zn}$ dopants (dotted lines), calculated electromagnetic wave intensity of the fundamental mode (black line). Heterostructure was grown by low-pressure MOVPE, with the layer sequence (from substrate): $\mathrm{n}^{+}$-GaAs buffer $(0.5 \mu \mathrm{m}) ; \mathrm{Al}_{.35} \mathrm{Ga}_{65} \mathrm{As}$ $\mathrm{n}$-cladding $(4.5 \mu \mathrm{m}$, the refractive-index-deep is due to the free-carrier contribution connected with higher Si-doping sublayer $\left(2 \times 10^{18} \mathrm{~cm}^{-3}\right)$ ); $\mathrm{n}$-AlGaAs gradient $(50 \mathrm{~nm}) ; \mathrm{n}-\mathrm{Al}_{.5} \mathrm{Ga}_{5}$ As barrier (antiguide, $50 \mathrm{~nm}$ ); undoped- $\mathrm{Al}_{.3} \mathrm{Ga}_{.7} \mathrm{As}$ waveguide $(0.4 \mu \mathrm{m})$ with centered InGaAs QW; $\mathrm{p}-\mathrm{Al}_{.5} \mathrm{Ga}_{5} \mathrm{As}$ barrier (antiguide, $50 \mathrm{~nm}) ; \mathrm{p}$-AlGaAs gradient $(50 \mathrm{~nm}) ; \mathrm{Al}_{.35} \mathrm{Ga}_{.65} \mathrm{As}$ p-cladding $(3.5 \mu \mathrm{m}$, the refractive-index-deep is due to the free-carrier contribution connected with higher $\mathrm{Zn}$-doping sublayer $\left.\left(1 \times 10^{18} \mathrm{~cm}^{-3}\right)\right)$; $\mathrm{p}^{+}$-GaAs cap $(0.2 \mu \mathrm{m})$. 
Their resonator lengths are $L=3 \mathrm{~mm}$ and the nominal widths of the active stripes are $W=20 \mu \mathrm{m}$. Symbols E, F, N denote different wafer processing implementations. The measured near-field (NF) patterns, shown in Fig. 2, reveal some differences, which will be taken into account in further analysis. Chips from the implementation $\mathrm{F}$ and $\mathrm{N}$ are prepared for observation of the spontaneous emission (EL) and thus have the n-contact windows above the active stripes. Our measurements showed that all devices exhibited threshold currents $0.24 \mathrm{~A}<I_{\text {th }}<0.4 \mathrm{~A}$ and incremental efficiencies $0.95 \mathrm{~W} / \mathrm{A}<S$ $<1.15 \mathrm{~W} / \mathrm{A}$.

The PMS and OC processes have been realized in the Denton's electron-beam evaporator INTEGRITY 29, equipped with an ion gun. All DLs have a metallic high-reflecting rear mirror deposited in the sequence (starting from bottom) $\mathrm{AlN} / \mathrm{TiO}_{2} / \mathrm{Ag} /$ $\mathrm{TiO}_{2} / \mathrm{AlN}$. The layers were reactively-, or e-beam-deposited, partially by shadow evap-
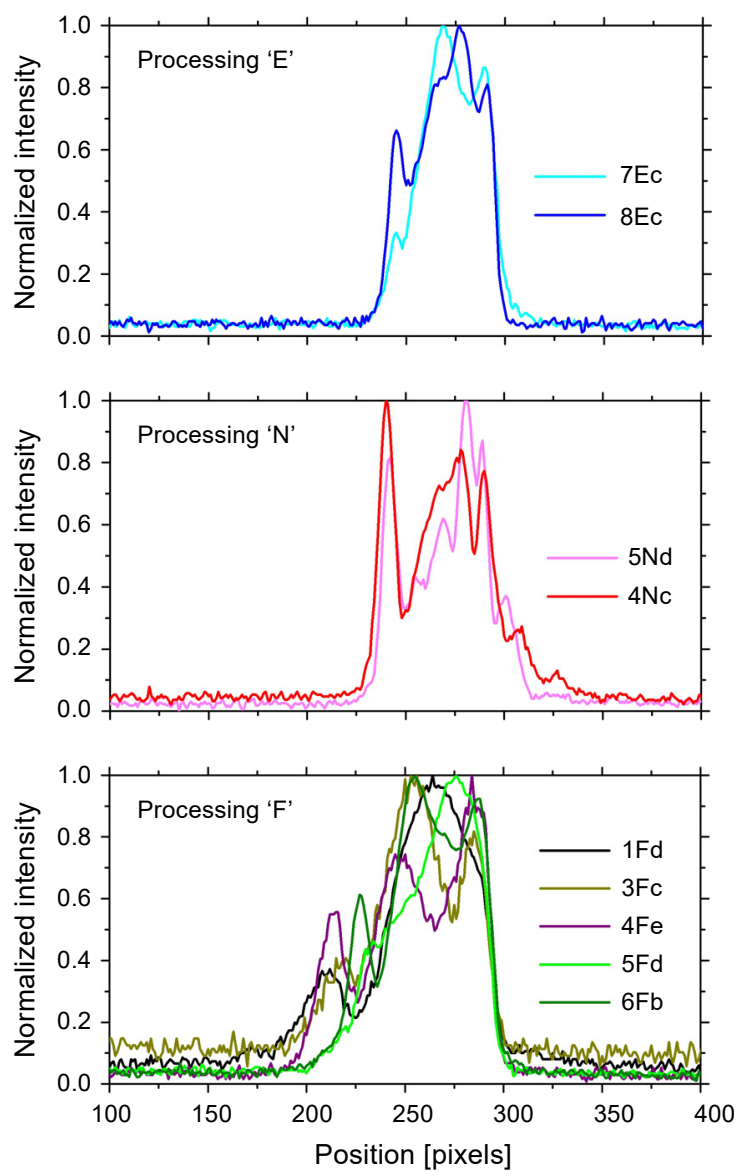

Fig. 2. Near field (NF) patterns for exemplary diode lasers manufactured from three wafer processing implementations $(\mathrm{E}, \mathrm{F}, \mathrm{N})$. The preceding number in the device's denotation stands for the number of version (PMS + OC, as described in Table 1) and the small letter behind denotes the individual chip. Note that in all measurements the distance between CCD camera and the front DL's mirror was kept constant. 
oration $[\underline{9}, \underline{10}]$. Front, low-reflecting AlN $(\sim \lambda / 4)$ coatings were reactively deposited. In the reactive processes (of e.g. AlN or $\mathrm{SiN}_{x}$ ), simultaneously e-beam-evaporated $\mathrm{Al}$ or Si and ion gun-launched $\mathrm{N}$ fluxes lead to the nitrides' deposition as a result of high -energy-stimulated chemical reaction. Different nitrogen flows were used, corresponding to the ion gun voltages $U_{\mathrm{D}} \cong 150 \mathrm{~V}$ and $U_{\mathrm{D}} \cong 80 \mathrm{~V}$.

In selected technological versions thin $(<10 \mathrm{~nm}) \mathrm{SiN}_{x}$ layers were deposited on the front and rear cleaved mirrors just after PMS process (in situ), and before OC deposition. The goal of using them seems to be a separation of OCs from passivated semiconductor surfaces $[\underline{1}, \underline{3}]$. The OCs (usually oxide layers: $\mathrm{Al}_{2} \mathrm{O}_{3}, \mathrm{TiO}_{2}, \mathrm{SiO}_{2}[\underline{3}]$; in [1] OC materials are not specified) are considered as a potential source of oxidation of (Al-containing) semiconductor mirror surface at high power emission. In our case, where OCs are nitrides, usefulness of these layers remains to be explained.

Technology of OCs as above was invariant for all devices.

The main differences in the successive experiments described below concerned the parameters of the cleaning and passivation of semiconductor mirror surfaces. These processes consisted in irradiating (bombardment) of semiconductor mirror surfaces with an ionized nitrogen or forming gas $\left(\mathrm{N}_{2}(94 \%)+\mathrm{H}_{2}(6 \%)\right)$. As a result of these actions [ $\left.\underline{3}, \underline{4}\right]$ :

- native oxides are removed (we expect the presence of hydrogen to intensify this effect),

- partial surface polishing is observed,

- due to the chemical reaction of the semiconductor surface with atomic nitrogen (launched by the ion gun), a very thin layer of native nitrides is formed together with the simultaneous disappearance of dangling bonds.

The effects described above lead to the improvement of the surface quality of mirrors and to the increase of the COMD threshold. In turn, it is known that the high energy of the $\mathrm{N}_{2}+\mathrm{H}_{2}$ or $\mathrm{N}_{2}$ beam causes radiation defects, which is a destructive effect. In this experiment we look for optimal conditions of all processes leading to obtaining more insusceptible mirrors. The processes are listed in Table 1, where we introduce the following convention. As it was mentioned before, letters E, F, N stand for wafer processing implementations. The number preceding the letter is for distinguishing PMS versions, described for each case in the separate row. Abbreviations AlN/... de-

T a b l e 1. The description of groups of DLs which underwent different mirror processing.

\begin{tabular}{cll}
\hline $\begin{array}{l}\text { Version } \\
\text { symbol }\end{array}$ & PSM & OCs \\
\hline $3-\mathrm{F}$ & $\mathrm{N}_{2}+\mathrm{H}_{2}$, flow $F=40 \mathrm{sccm}$, exposure time $\tau=5 \mathrm{~min}$ & $\mathrm{AlN} / \ldots$ \\
$4-\mathrm{F}$ & $\mathrm{N}_{2}+\mathrm{H}_{2}, F=40 \mathrm{sccm}, \tau=10 \mathrm{~min}$ & $\mathrm{AlN} / \ldots$ \\
$5-\mathrm{F}$ & $\mathrm{N}_{2}+\mathrm{H}_{2}, F=40 \mathrm{sccm}, \tau=5 \mathrm{~min}$ & $\mathrm{SiN}_{x}\left(U_{\mathrm{D}}=150 \mathrm{~V}\right)$, then $\mathrm{AlN} / \ldots$ \\
$6-\mathrm{F}$ & $\mathrm{N}_{2}+\mathrm{H}_{2}, F=150 \mathrm{sccm}, \tau=10 \mathrm{~min}$ & $\mathrm{SiN}_{x}\left(U_{\mathrm{D}}=150 \mathrm{~V}\right)$, then $\mathrm{AlN} / \ldots$ \\
$7-\mathrm{E}$ & $\mathrm{N}_{2}+\mathrm{H}_{2}, F=150 \mathrm{sccm}, \tau=5 \mathrm{~min}$ & $\mathrm{SiN}_{x}\left(U_{\mathrm{D}}=150 \mathrm{~V}\right)$, then AlN $/ \ldots$ \\
$8-\mathrm{E}$ & $\mathrm{N}_{2}+\mathrm{H}_{2}, F=40 \mathrm{sccm}, \tau=10 \mathrm{~min}$ & $\mathrm{SiN}_{x}\left(U_{\mathrm{D}}=150 \mathrm{~V}\right)$, then AlN $/ \ldots$ \\
$9-\mathrm{N}$ & $\mathrm{N}_{2}+\mathrm{H}_{2}, F=40 \mathrm{sccm}, \tau=5 \mathrm{~min}$ & $\mathrm{SiN}_{x}\left(U_{\mathrm{D}}=80 \mathrm{~V}\right)$, then AlN $/ \ldots$ \\
$10-\mathrm{N}$ & $\mathrm{N}_{2}, F=150 \mathrm{sccm}, \tau=10 \mathrm{~min}$ & $\mathrm{AlN} \ldots$ \\
\hline
\end{tabular}


note $\mathrm{AlN}(\sim \lambda / 4)$ layer on the front or $\mathrm{AlN} / \mathrm{TiO}_{2} / \mathrm{Ag} / \mathrm{TiO}_{2} / \mathrm{AlN}$ layer on the rear mirror, respectively. Note that all PMS versions have been applied symmetrically to both mirrors and followed by respective in situ OCs depositions.

The voltage $U_{\mathrm{D}}$ measured at the ion gun is the parameter resulting from gun current (whose optimum value was found previously) and the gas flow $F$. It corresponds approximately to the energy of the atoms (after deionization) bombarding the semiconductor mirror surfaces. In this experiment $U_{\mathrm{D}} \cong 85 \mathrm{~V}$ at $F=40 \mathrm{sccm}\left(\mathrm{N}_{2}+\mathrm{H}_{2}\right.$ or $\left.\mathrm{N}_{2}\right)$ and $U_{\mathrm{D}} \cong 52 \mathrm{~V}$ at $F=150 \mathrm{sccm}$. The values of parameters chosen in our experiments can be explained as below. The flow must not:

- exceed $150 \mathrm{sccm}$ because of the limited efficiency of the cryogenic pump and the fact that too high pressure of gases in the reaction chamber would disable the electron gun. This results in the lowest $U_{\mathrm{D}}$ in the experiment;

- be lower than $40 \mathrm{sccm}$ because the resultant $U_{\mathrm{D}}>85 \mathrm{~V}$ in such case increases the risk of serious mirror damage.

Optical measurements were done with the usage of a pulse generator - the current source Avtech AV-107D-B providing current up to $20 \mathrm{~A}$. We investigated unmounted chips in order to avoid additional natural diversification arising during mounting process. DLs operated in pulse regime with the pulse width $t=1 \mu \mathrm{s}$ and repetition $T=1 \mathrm{~ms}$. Such a regime minimized thermal effects. For detection of emitted light versus driving current, the Si p-i-n diode with $1 \mathrm{~cm}^{2}$ photosensitive area and set of attenuating filters was used. The optical pulse power $P$ was recorded on one channel of the TECTRONIX TDS 1012B oscilloscope, while on another - the voltage across the diode pulse. Light power measurement was carried out by measuring the maximum value of the optical pulse. Simultaneously, oscillograms of both pulses were recorded as functions of the amplitude $I$ of the current pulse. The actual value of the optical power in the pulse was determined based on previous calibrations.

After measurements of $P-I-V$ pulse characteristics leading to possible COD effect, the DLs for which the degradation effect was observed were mounted on copper submounts allowing for detecting and recording EL outgoing through the windows in n-contacts. The goal was to identify the mechanism of degradation. The same goal motivated SEM observations of front mirrors of selected chips after COD effect.

\section{Results and discussion}

The measurements of COD threshold presented in Table 2 provide important information about quality of mirror processing technology. The results are ranked from the best DLs, for which the degradation did not occur for pumping currents up to $20 \mathrm{~A}$, to the worst, i.e. exhibiting lowest COD thresholds.

To improve visibility, part of data contained in Table 2 is displayed in Fig. 3, in the form of "COD coordinates" - the optical power versus current pulse amplitudes at which COD has been recorded. The group of devices not degraded up to current pulse $20 \mathrm{~A}$ is marked with frame. Type of defects (front mirror (FM), rear mirror (RM) and inside the resonator (INR)) and COD data spread are seen. 
$\mathrm{T}$ a b 1 e 2. The experimental results ranked from the best to the worst DL mirror protection. Abbreviations used: front mirror (FM), rear mirror (RM) and inside the resonator (INR).

\begin{tabular}{|c|c|c|c|c|}
\hline \multirow{3}{*}{ Version } & \multicolumn{3}{|c|}{ DL's number } & \multirow{3}{*}{$\begin{array}{l}\text { Remarks: } \\
\text { the decrease of light power within impulse, } \\
\text { thermal distortion of } P-I \text { characteristics }\end{array}$} \\
\hline & 1 & 2 & 3 & \\
\hline & $\begin{array}{l}P @ 20 \text { A (no C } \\
P @ I_{\mathrm{COD}}, \mathrm{COD}\end{array}$ & $\begin{array}{l}\text { OD) or } \\
\text { mechanism }\end{array}$ & & \\
\hline$\overline{9-\mathrm{N}}$ & 12.5W@20A & 12.5W@20A & 12W@20A & No slope \\
\hline$\overline{10-\mathrm{N}}$ & 13.3W@20A & 14.1W@20A & 13.2W@20A & Moderate slope \\
\hline $7-\mathrm{E}$ & 11.5W@20A & 10.9W@20A & & $\begin{array}{l}\text { Relative large slope, } \\
\text { larger thermal curvature, } \\
\text { no COMD at FM (according to } \\
\text { SEM picture) }\end{array}$ \\
\hline $3-\mathrm{F}$ & 11.6W@20A & $\begin{array}{l}\text { 11.6W@19.5A } \\
\text { COD INR }\end{array}$ & $\begin{array}{l}\text { 11.3W@17A } \\
\text { COMD FM }\end{array}$ & Very large slope \\
\hline $5-\mathrm{F}$ & $\begin{array}{l}\text { 10W@17.5A } \\
\text { COD INR }\end{array}$ & $\begin{array}{l}\text { 10.1W@14.5A } \\
\text { COD INR }\end{array}$ & $\begin{array}{l}\text { 8.9W@12A } \\
\text { COD INR }\end{array}$ & Large slope \\
\hline $4-\mathrm{F}$ & $\begin{array}{l}\text { 8.7W@13.5A } \\
\text { COMD RM }\end{array}$ & $\begin{array}{l}\text { 8.5W@11A } \\
\text { COMD FM }\end{array}$ & $\begin{array}{l}\text { 7.9W@10A } \\
\text { COMD RM }\end{array}$ & $\begin{array}{l}\text { Not observed at such low level } \\
\text { of pumping }\end{array}$ \\
\hline $6-\mathrm{F}$ & $\begin{array}{l}8.2 \mathrm{~W} @ 10 \mathrm{~A} \\
\text { COMD FM }\end{array}$ & $\begin{array}{l}\text { 8.4W@11.5A } \\
\text { COMD FM }\end{array}$ & $\begin{array}{l}\text { 8W@10A } \\
\text { COMD FM }\end{array}$ & $\begin{array}{l}\text { Not observed at such low level } \\
\text { of pumping }\end{array}$ \\
\hline $8-\mathrm{E}$ & $\begin{array}{l}\text { 7.6W@11A } \\
\text { COMD FM }\end{array}$ & $\begin{array}{l}\text { 7.3W@10A } \\
\text { COMD FM }\end{array}$ & $\begin{array}{l}\text { 6.8W@9.5A } \\
\text { COMD FM }\end{array}$ & $\begin{array}{l}\text { COMD at FM (according to } \\
\text { SEM picture) }\end{array}$ \\
\hline
\end{tabular}

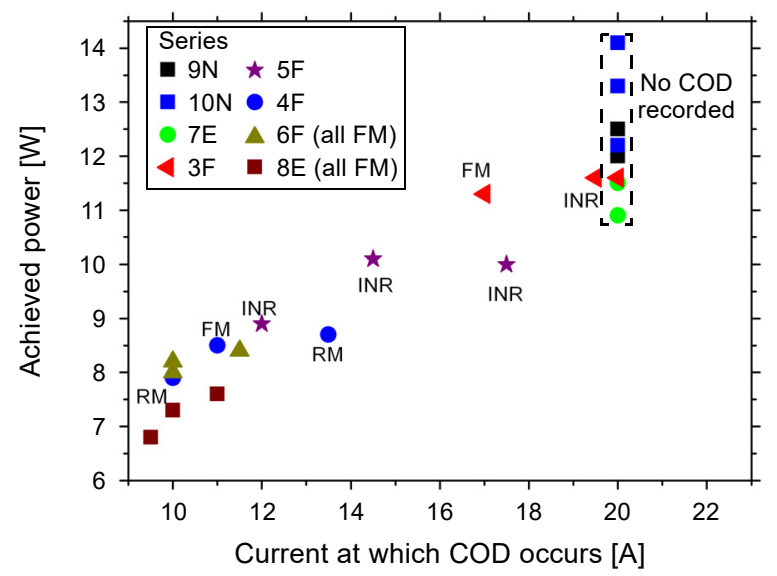

Fig. 3. COD-coordinates of DLs investigated in the experiment.

For each version 3 or 4 chips were measured. Devices exhibiting defects other than those related to mirrors were omitted.

$P-I-V$ curves for DL no. 1 from technological version 9-N (according to convention introduced here: 9-N-1) and optical and voltage pulse oscillograms are shown in Fig. 4. At high drive currents $\left(I \gg I_{\mathrm{th}}\right)$ some bowing (saturation) of $P-I-V$ characteristics is visible (gradual decrease of incremental efficiency). It can be explained in terms of 


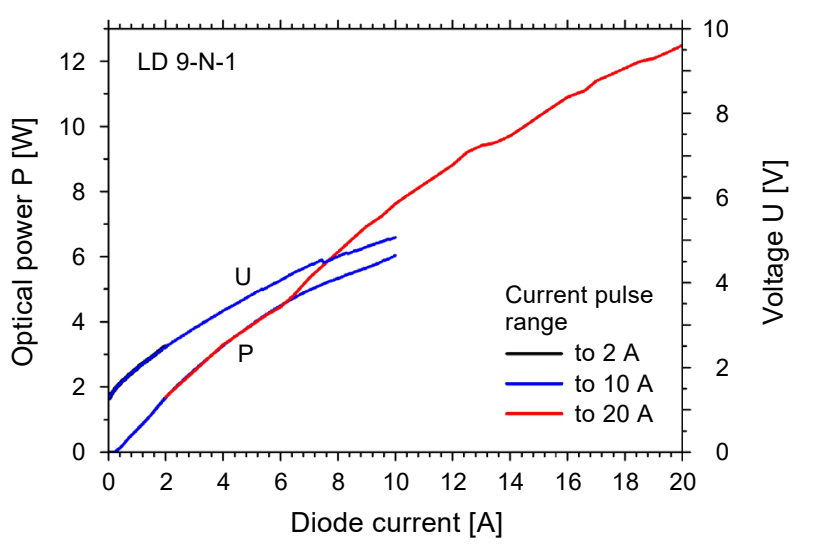

a
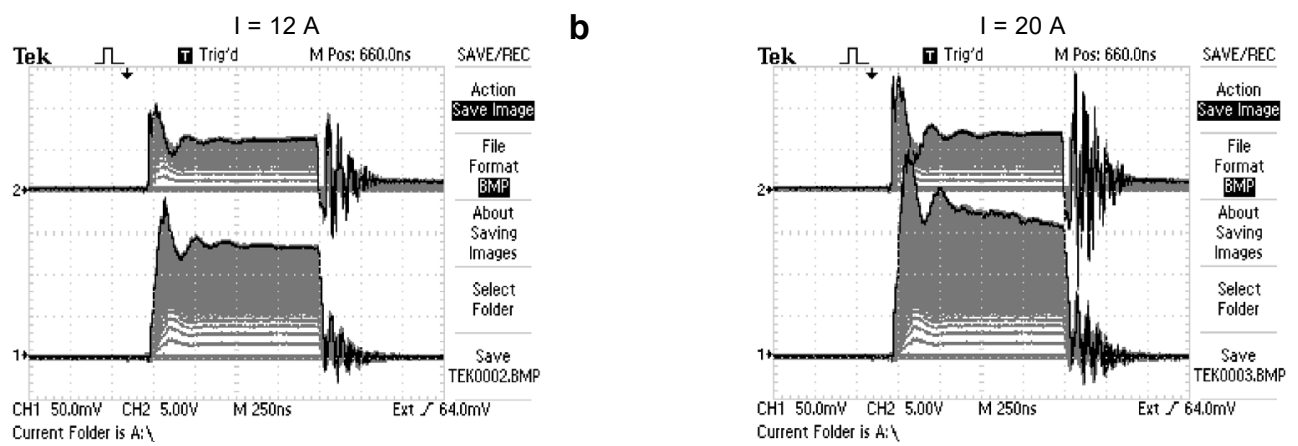

Fig. 4. Pulsed $P-I-V$ characteristics of 9-N-1 diode. Light power $P$ is recorded from the maximal point of the oscillogram (lower trace, at front of the pulse) - a. Oscillograms of the light pulse (lower trace) and voltage pulse (upper trace). Both measurements done at $I=12 \mathrm{~A}-\mathbf{b}$. Oscillograms as in $\mathbf{b}$, measured at $I=20$ A. Fast oscillations just after switching off the power supply pulse are the consequence of an induction loop of the probe and should be treated as an artefact. Analogical oscillations after the optical pulse are induced in the photodiode circuit - c.

decreasing radiative recombination efficiency at high injection levels [11]. A further contribution to this phenomenon can be an additional loss mechanism and increase of the temperature during a pulse. Point measurement of optical power applied here (at the maximum point on the front edge of the pulse trace) eliminates the influence of thermal effects during the pulse on the $P-I$ characteristics. By contrast, this effect can be seen on oscillograms (Figs. $4 \mathbf{b}$ and $4 \mathbf{c}$ ) recorded in the "persistence" mode.

The black line stands for the last recorded trace at pumping levels $I=12 \mathrm{~A}$ and $I=20$ A in Figs. $4 \mathbf{b}$ and $4 \mathbf{c}$, respectively, while previous oscillograms are to be found in grey, sometimes inhomogeneous, background. At $I=12$ A the ridges (tops) of optical and voltage pulses are flat (except initial oscillations) and so heating of the structure is a minor effect. In contrast, at $I=20$ A the temperature growth during the pulse is noticeable and manifests itself by gradual decrease of light power.

DLs of technological version 9-N exhibit the best characteristics and do not undergo COD up to $I=20 \mathrm{~A}$. Similarly, the $10-\mathrm{N}$ version can also be positively evaluated. 


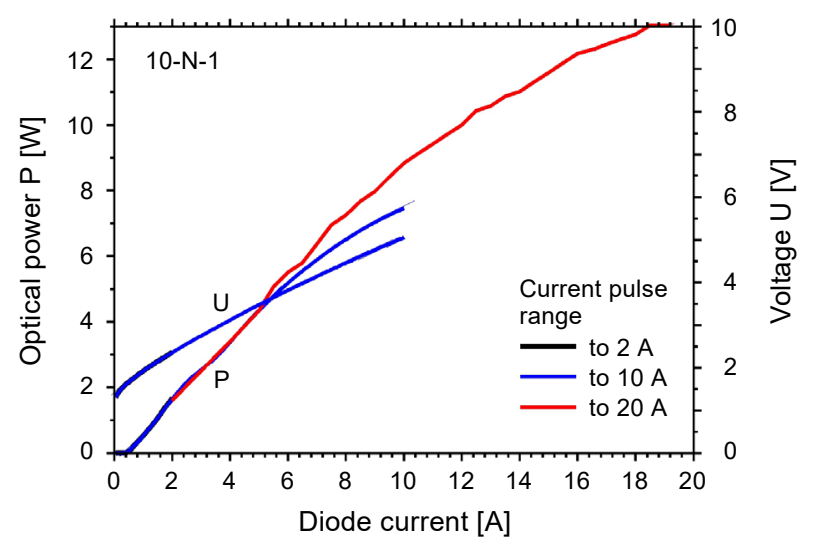

a
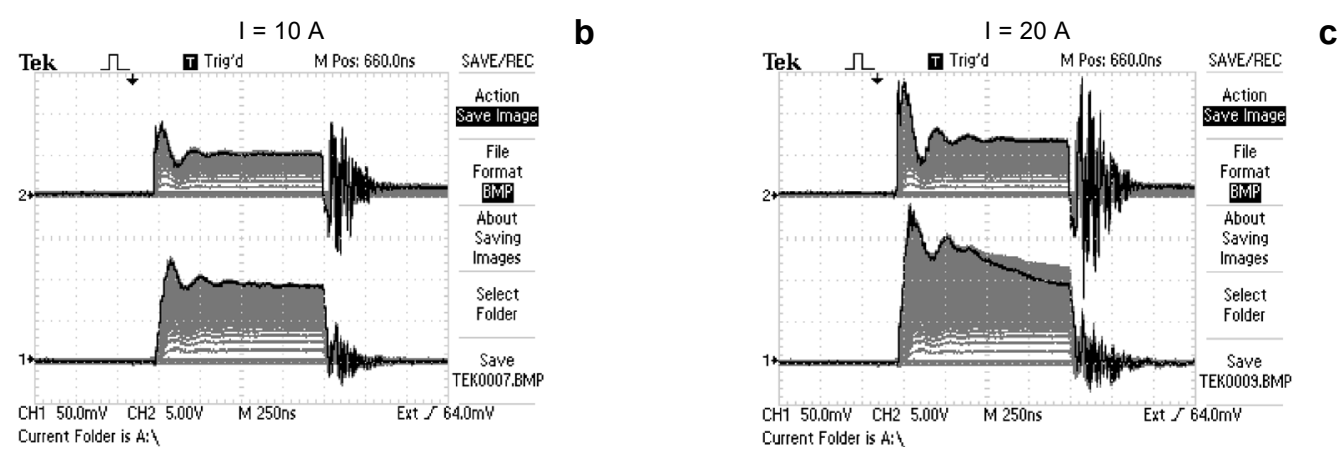

Fig. 5. Analogically as in Fig. 4, done for 10-N-1 diode. Faster drop of light power at $I=20$ A can be well seen. The top of the pulse decreases faster as pumping increases.

Figure 5 shows characteristics of the $10-\mathrm{N}-1$ diode. However, for this device saturation of light power is visible at high pumping level $(I=20 \mathrm{~A})$. Also oscillogram from Fig. 5c shows more rapid thermal decrease of light power during the pulse at $I=20 \mathrm{~A}$ than in cases of earlier, lower pumping levels. Heating of the structure can be a volumetric effect, due to non-radiative processes in the entire resonator, or a surface effect, initiated by absorption of radiation by defects at cleaved facets. In the optical measurements presented so far, these mechanisms are indistinguishable.

Similar or slightly faster thermal decreases of light power during the pulse have been observed for DLs of 7-E version (Fig. 6). Lower incremental efficiency of DLs from this version results in lower light power at $I=20$ A. Note however that power density at the mirror may be similar as in case of $9-\mathrm{N}$ or $10-\mathrm{N}$ because of the lowest actual width of a contact stripe (Fig. 2). While comparing DLs from versions $10-\mathrm{N}$ and 7-E, two important differences should be pointed out. The latter devices underwent shorter etching time, which may attenuate the effect of passivation. Moreover, the $\mathrm{SiN}_{x}$ layer was deposited with the usage of high energy nitrogen beam $\left(U_{\mathrm{D}}=150 \mathrm{~V}\right)$. Radiation defects, generated during this process, may enhance absorption of the emitted light at mirrors due to band gap shrinkage caused by increasing temperature. These phenomena 

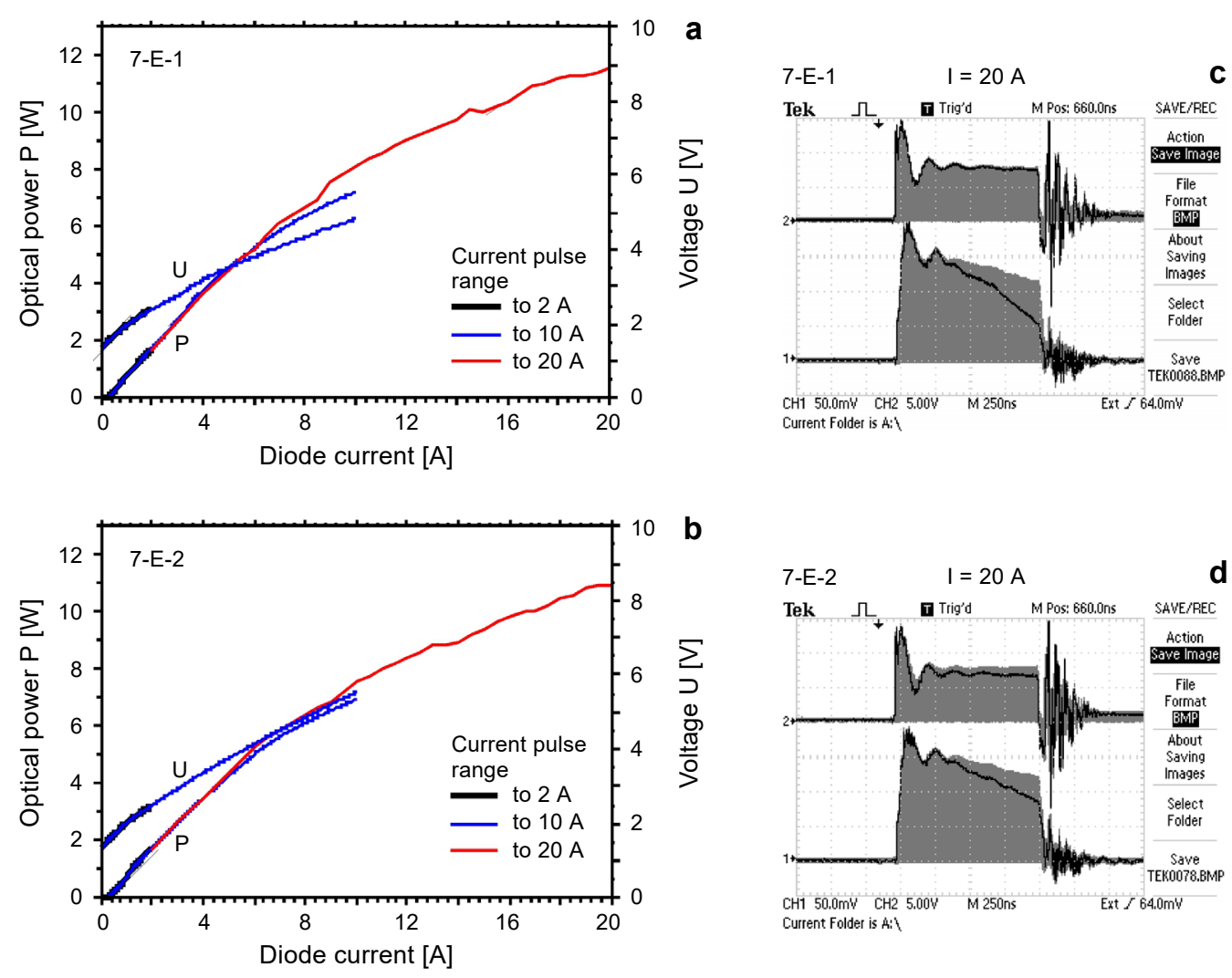

Fig. 6. Pulsed $P-I-V$ characteristics of 7-E-1 (a) and 7-E-2 (b) diodes. Oscillograms of optical and voltage pulses for 7-E-1 (c) and 7-E-2 (d) DLs at $I=20$ A.

can explain lowering of incremental efficiency and increasing of temperature during the pulse.

For version 3-F COD has been observed at pumping currents close to 20 A (Fig. 7). Depending on the chip, the degradation affected the front mirror or the inner part of the resonator. The investigated devices differ from 9-N only in the lack of $\mathrm{SiN}_{x}$ layer. The positive influence of this layer had been reported earlier $[\underline{1}, \underline{3}]$. However, the layer is adjacent to the semiconductor surface, so it should be deposited carefully, i.e. using low energy to avoid the generation of defects and the damage of passivation layer. Another thing is to notice relatively large differences between wafer processing implementations of E, F, N (Fig. 2). In particular, we suggest that devices from group F should be compared with one another, while loosely relating to those marked by $\mathrm{E}$ and $\mathrm{N}$.

Recording of EL image through the n-contact window allows us to identify the COD mechanism. Figure 8a shows such image for DL 3-F-2. The dark line in the central part of the resonator reveals the degradation not related to mirrors. This fact suggests that, in this device, facet coatings proved their effectiveness. This refers back to 

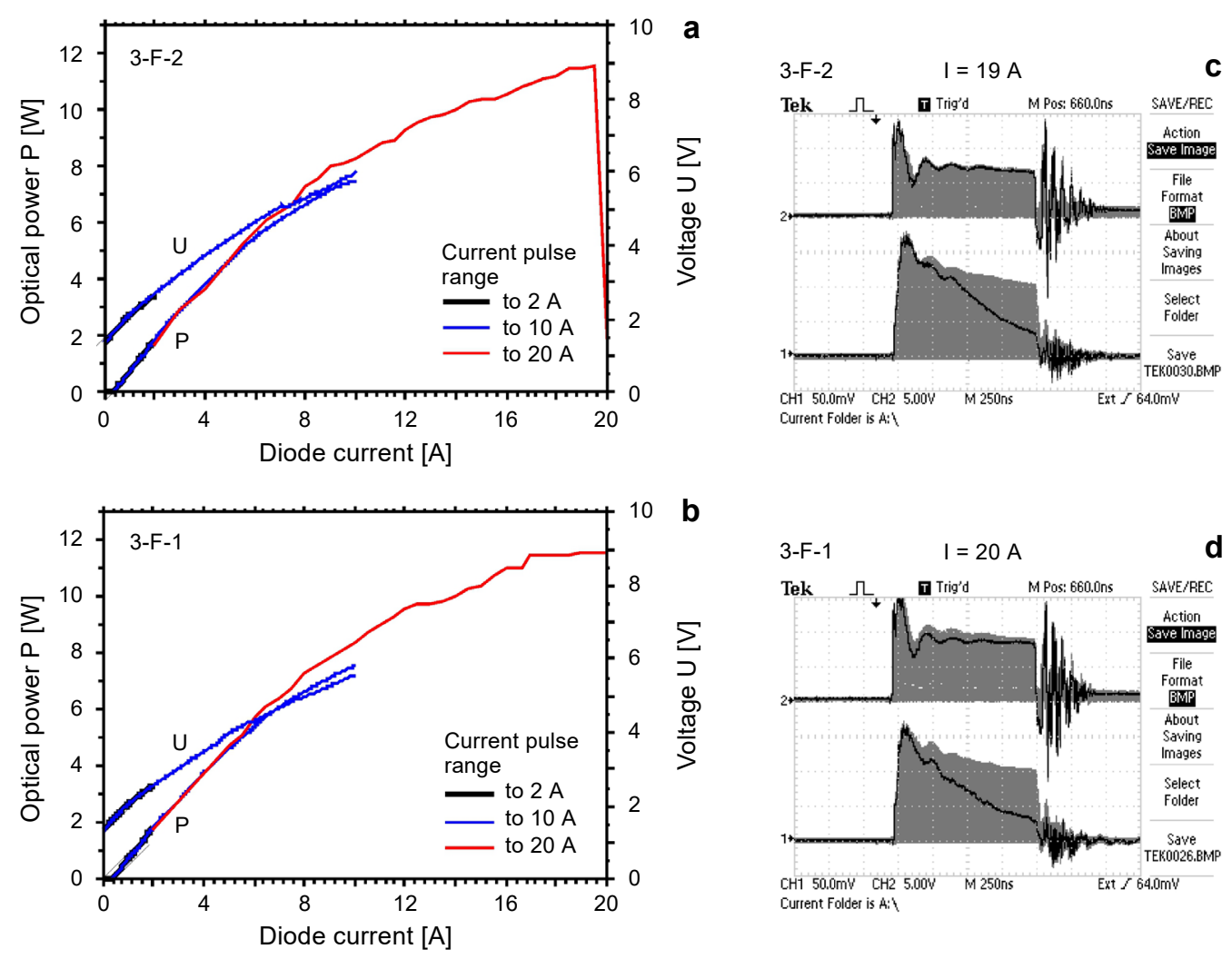

Fig. 7. Pulsed $P-I-V$ characteristics of 3-F-2 (a) and 3-F-1 (b) diodes. Oscillograms of optical and voltage pulses for 3-F-2 DL at $I=19$ A (just below the COD level) (c), and 3-F-1 DL at $I=20$ A (d).

the case in which COD occurs at the section of $P-I$ characteristics, where $P$ decreases after reaching its maximal value [ $[$ ]

Figure $8 \mathbf{b}$ shows the electroluminescence image for DL 3-F-3. The effect of COMD at the front mirror can be clearly seen. However, looking at the $P$ - $I$ curve (Fig. 8 c), we
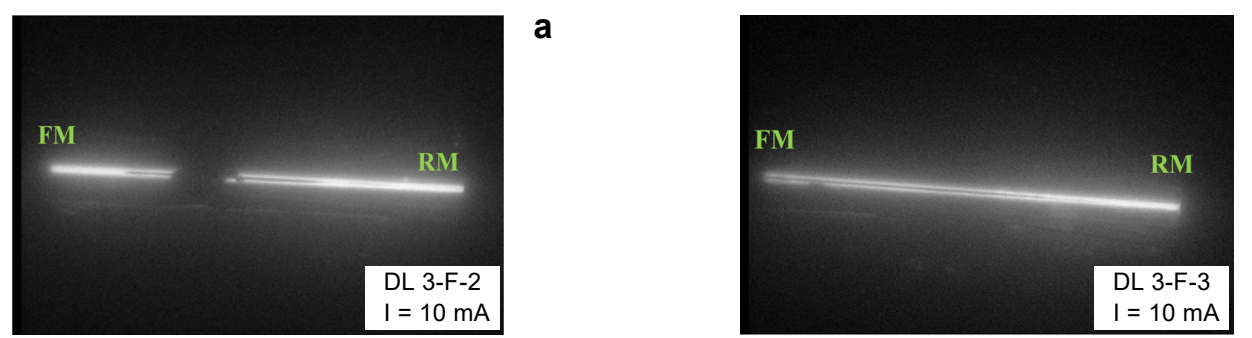

b

Fig. 8. Electroluminescence images recorded through the windows in n-contacts of 3-F-2 and 3-F-3 DLs after degradation appearing through dark lines along the resonator axis. Big dark spot at $\mathbf{a}$ is an artifact, namely the consequence of polluting the sample during the process of mounting (a, b ). $P-I-V$ characteristics of 3-F-3 DL which underwent COMD (c). 


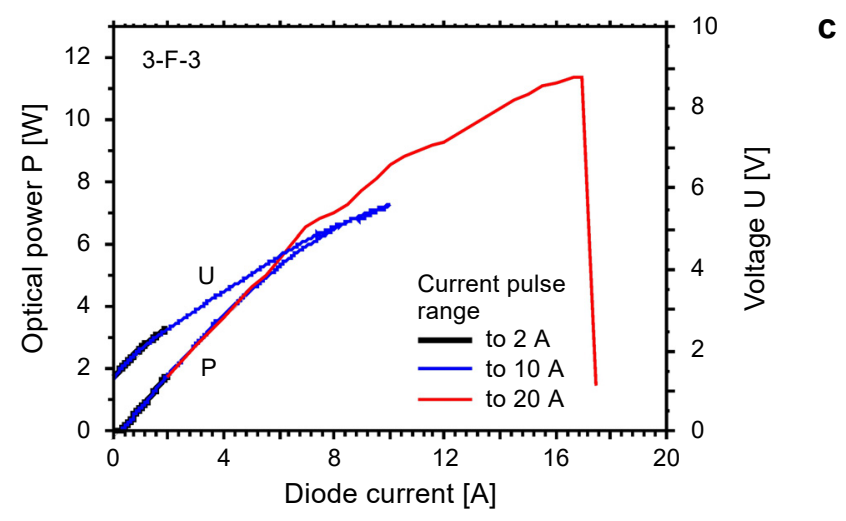

Fig. 8. Continued.

note that, due to high efficiency of the investigated device, COMD threshold does not diverge too much from light powers reached at high driving $(I=20 \mathrm{~A})$ for other DLs. Note that COMD in this case could be further enhanced by strong heating of the structure during a pulse. Thus PMS and OC applied to DL 3-F-3 to protect mirrors can also be acknowledged as satisfactory.

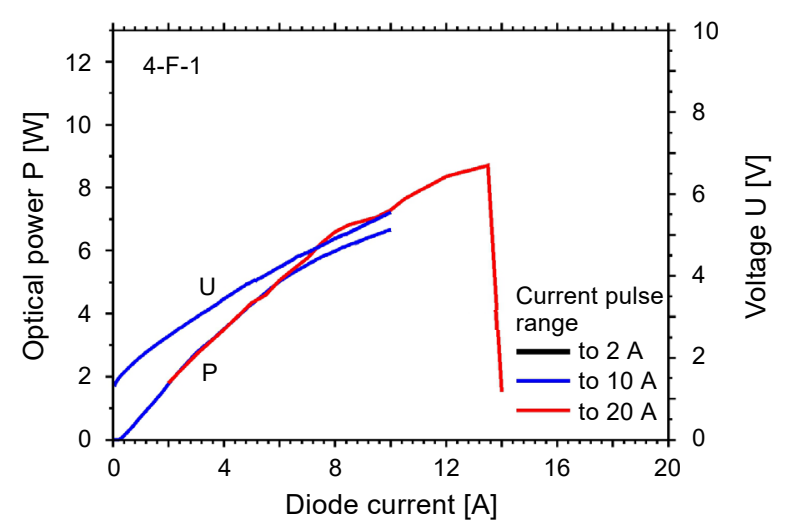

a

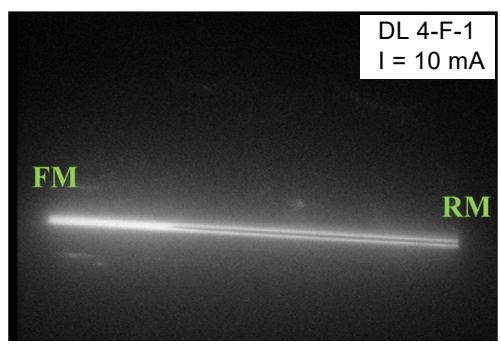

b

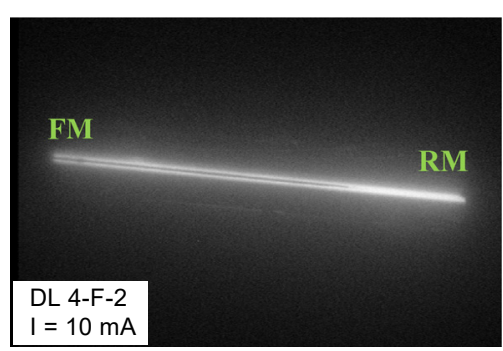

C

Fig. 9. Characteristics $P-I-V$ of 4-F-1 DL (a). EL images recorded through the window in n-contacts of 4-F-1 and 4-F-2 DLs after degradation $(\mathbf{b}, \mathbf{c})$. 
Mirror protection in subsequent versions of investigated DLs, namely 5-F, 4-F, 6-F and 8-E, cannot be considered successful. In case of 4-F (Fig. 9) too long (10 min) time of passivation by high energy $\mathrm{N}_{2}+\mathrm{H}_{2}$ beam $\left(U_{\mathrm{D}}=85 \mathrm{~V}\right)$ was applied. The destructive influence of high energy deposition of $\operatorname{SiN}_{x}$ layer $\left(U_{\mathrm{D}}=150 \mathrm{~V}\right)$ manifested in versions 5-F, 6-F and 8-E. The process turns out to be invasive and leads to COMD of the front mirror. The most unfavorable sequence of processes seems to appear in case of $8-\mathrm{E}$, for which high energetic and extended passivation was applied and then high energy deposition of $\mathrm{SiN}_{x}$ was used.

Large number of defects generated in all these processes resulted in low efficiencies and low COMD thresholds as seen in Fig. 10a. Figure 10b shows the electroluminescence image of COMD initiated at the front mirror of DL from version 6-F. SEM picture of this mirror is presented in Fig. 10c. Similar SEM picture of COMD can be seen at the front mirror of DL from version 8-E-1 (Fig. 10d). Local damage of mirror corresponds with the maximum intensity of lateral optical mode, which can be stated after analyzing the appropriate NF profile from Fig. 2.
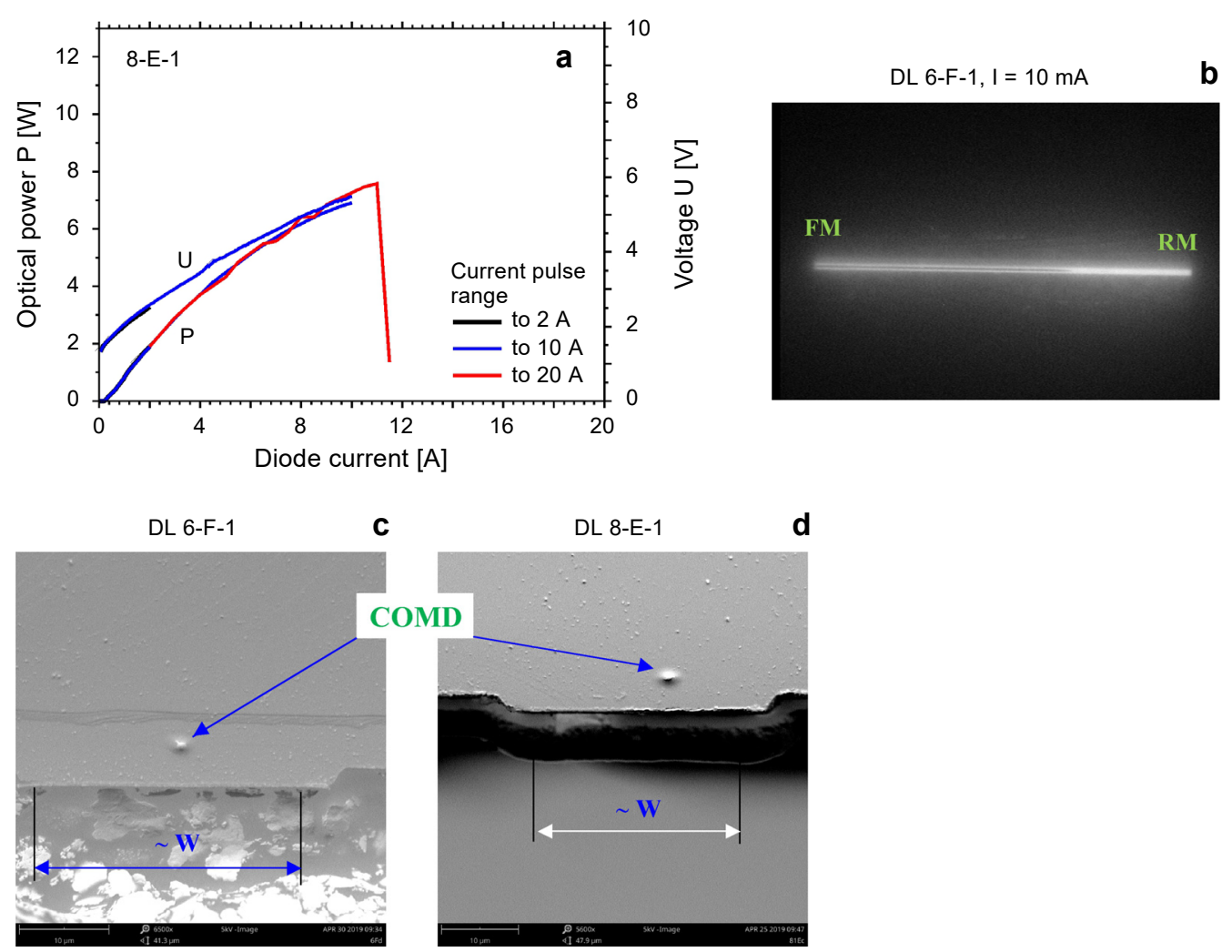

Fig. 10. $P-I-V$ characteristics of $8-E-1$ DL (a). EL image after degradation initiated at the front mirror and corresponding COMD picture taken by SEM for DL 6-F-1 (b, c). SEM photograph of 8-E-1 DL front mirror after degradation initiated on this mirror $(\mathbf{d})$. 


\section{Conclusions}

A few tips on technology of DLs' mirror protection can be formulated. PMS should remove native oxides, create a thin layer of native nitrides and saturate the dangling bonds. Subsequent deposition of OC should not damage already processed surface. These criteria are fulfilled by devices from versions $9-\mathrm{N}, 10-\mathrm{N}$ and - partially $-7-\mathrm{N}$ and 3-F. It is important to use a low energy etching beam resulting from intensive gas flow (approximate values of parameters $U_{\mathrm{D}} \cong 50 \mathrm{~V}$ at $F=150 \mathrm{sccm}, \tau=10 \mathrm{~min}$ ) or sufficiently short exposure in case of weak flow and higher energy (approximate values of parameters $U_{\mathrm{D}} \cong 80 \mathrm{~V}$ at $F=40 \mathrm{sccm}, \tau=5 \mathrm{~min}$ ).

Thin $(<10 \mathrm{~nm}) \mathrm{SiN}_{x}$ layer deposited immediately after PMS (in situ) seems to be useful. However, attempts to decrease the energy of its reactive deposition should be undertaken.

The role of hydrogen flow during PMS is still unclear. There is no evidence of its destructiveness, but - on the other hand - the question of its usefulness is still unanswered.

On the other hand, our investigations indicated the most invasive (and thus destructive) elements of technological process, namely long PMS by a high energy beam $\left(U_{\mathrm{D}} \cong 80 \mathrm{~V}\right.$ at $F=40 \mathrm{sccm}, \tau=10 \mathrm{~min}$ ) and high energy deposition of $\operatorname{SiN}_{x}$ layer that have been applied in versions 6-F and 8-E.

Taking $P @ 20 \mathrm{~A}=13 \mathrm{~W}$ in optical pulse for undegraded DLs (averaged from Table 2 and Fig. 3), $W=20 \mu \mathrm{m}$, and the vertical mode size $d / \Gamma=0.794 \mu \mathrm{m}$ (Fig. 1), one obtains COD threshold above $P /(W \cdot d / \Gamma) \cong 82 \mathrm{MW} / \mathrm{cm}^{2}$. For comparison, for pulse operated narrow-stripe $(W=3 \mu \mathrm{m})$ DLs of similar quantum energy and PMS by nitridation, recorded COD threshold was $0.35 \mathrm{~W}$ [3] . Assuming typical $d / \Gamma=0.5 \mu \mathrm{m}$ (parameter not given by the Authors), one obtains COD threshold density of $23 \mathrm{MW} / \mathrm{cm}^{2}$. These results can be considered comparable, especially that the driving pulse parameters $(t, T)$ are not given too. COD thresholds of CW-operated DLs are lower compared to pulse operated devices (depending on $t / T$ ). For typical COD level of $20 \mathrm{~W}$ in CW operation of high-power, $980 \mathrm{~nm}$ emitting LDs of $W=100 \mu \mathrm{m}$ and $d / \Gamma=1 \mu \mathrm{m}$ [1], the resulting COD threshold density is $20 \mathrm{MW} / \mathrm{cm}^{2}$. In general, there is quite large inconsistency of results presented by various authors, due to diversity of techniques of mirrors' protection, operation and testing conditions, etc.

As the subject of further research we can point out finding the optimal parameters of mirror protection more precisely.

Acknowledgements - The authors thank Mr. Michał Gajewski for carrying out the passivation and deposition processes of optical coatings of diode lasers and his help in the analysis of processes' parameters. The work is financed by the Research Network Łukasiewicz - ITME as a part of the project entitled Optimization of diode laser coating technology to maximize the threshold of catastrophic optical degradation (COD). 


\section{References}

[1] Yanson D., Levi M., Shamay M., Tesler R., Rappaport N., Don Y., Karni Y., Schnitzer I., Sicron N., SHuSTERMAn S., Facet engineering of high power single emitters, Proceedings of SPIE 7918, 2011, article 79180Z, DOI: $10.1117 / 12.876261$.

[2] Dąbrowska E., Teodorczyk M., Lipińska L., Krzyżak K., Dąbrowski A., Sobczak G., KozŁowska A., MatKowski P., MŁożniak A., MaląG A., Zastosowanie tlenku grafenu i grafenu w technologii diod laserowych, Przegląd Elektrotechniczny, R91, No. 9, 2015, pp. 1-4 (in Polish).

[3] Lambert R.W., Ayling T., Hendry A.F., Carson J.M., Barrow D.A., McHendry S., Scott C.J., McKee A., Meredith W., Facet-passivation processes for the improvement of Al-containing semiconductor laser diodes, Journal of Lightwave Technology 24(2), 2006, pp. 956-961, DOI: 10.1109 / JLT.2005.861916.

[4] Silfvenius C., Blixt P., Lindström C., Feitisch A., Native-nitride passivation eliminates facet failure, Laser Focus World 39, 2003, pp. 69-73.

[5] JАСов J., ChIN A., Innovative facet passivation for high-brightness laser diodes, Final Report, Grant No. W911NF-12-C-0071, November 2015.

[6] Bessolov V.N., Lebedev M.V., Shernyakov Y.M., Tsarenkov B.V., Sulfur passivation on InGaAs/ AlGaAs SQW laser (977 nm) facets in alcohol-based solutions, Materials Science and Engineering: B 44(1-3), 1997, pp. 380-382, DOI: 10.1016/S0921-5107(96)01817-X.

[7] Su Y.K., Wang H.C., Lin C.L., Chen W.B., Chen S.M., Improvement of AlGaInP light emitting diode by sulfide passivation, IEEE Photonics Technology Letters 15(10), 2003, pp. 1345-1347, DOI: 10.1109/LPT.2003.818064.

[8] Dąbrowska E., Maląg A., Teodorczyk M., Krzyżak K., Gajewski M., Możliwości poprawy niezawodności diod i matryc laserowych na pasmo $960 \mathrm{~nm}$, Report on the Implementation of the Statutory Work, ITME, Warszawa, 2018 (in Polish).

[9] TeOdorczyк M., Gajewski M., Technologia napylania metalowych warstw optycznych na lustra laserów pótprzewodnikowych, Technological Instruction ITME, 2011 (in Polish, unpublished).

[10] Teodorczyk M., Maląg A., Dąbrowska E., Gajewski M., Sobczak G., Konstrukcja pokrycia tylnego lustra lasera pótprzewodnikowego, zwłaszcza z emisją krawędziowa, i sposób wytwarzania pokrycia tylnego lustra lasera pótprzewodnikowego, zwłaszcza z emisją krawędziowa, Polish Patent PAT.229711, granted on September 10, 2018.

[11] Lyutetskil A.V., Borshchev K.S., Pikhtin N.A., Slipchenko S.O., Sokolova Z.N., Tarasov I.S., Contribution of Auger recombination to saturation of the light-current characteristics in high-power laser diodes $(\lambda=1.0-1.9 \mu \mathrm{m})$, Semiconductors 42(1), 2008, pp. 104-111, DOI: $10.1134 / \mathrm{S} 1063782608010156$. 